\title{
Regulation of Phosphoinositide Levels in the Retina by Protein Tyrosine Phosphatase 1B and Growth Factor Receptor-Bound Protein 14
}

\author{
Raju V. S. Rajala ${ }^{1,2,3,4, *(D)}$, Austin McCauley ${ }^{1,4}$, Rahul Rajala ${ }^{3,5}{ }^{(D)}$, Kenneth Teel ${ }^{1,4}$ and Ammaji Rajala ${ }^{1,4}$ \\ 1 Department of Ophthalmology, University of Oklahoma Health Sciences Center, \\ Oklahoma City, OK 73104, USA; austin-mccauley@ouhsc.edu (A.M.); kenneth-teel@ouhsc.edu (K.T.); \\ ammaji-rajala@ouhsc.edu (A.R.) \\ 2 Department of Physiology, University of Oklahoma Health Sciences Center, Oklahoma City, OK 73104, USA \\ 3 Department of Cell Biology, University of Oklahoma Health Sciences Center, Oklahoma City, OK 73104, USA; \\ rahul-rajala@omrf.org \\ 4 Dean McGee Eye Institute, Oklahoma City, OK 73104, USA \\ 5 Cardiovascular Biology Program, Oklahoma Medical Research Foundation, Oklahoma City, OK 73104, USA \\ * Correspondence: raju-rajala@ouhsc.edu; Tel.: +1-405-271-8255; Fax: +1-405-271-8128
}

check for updates

Citation: Rajala, R.V.S.; McCauley,

A.; Rajala, R.; Teel, K.; Rajala, A.

Regulation of Phosphoinositide

Levels in the Retina by Protein

Tyrosine Phosphatase 1B and Growth Factor Receptor-Bound Protein 14. Biomolecules 2021, 11, 602. https:// doi.org/10.3390/biom11040602

Academic Editors: Irene Faenza and Hemant Khanna

Received: 7 March 2021

Accepted: 15 April 2021

Published: 19 April 2021

Publisher's Note: MDPI stays neutral with regard to jurisdictional claims in published maps and institutional affiliations.

Copyright: (c) 2021 by the authors. Licensee MDPI, Basel, Switzerland. This article is an open access article distributed under the terms and conditions of the Creative Commons Attribution (CC BY) license (https:/ / creativecommons.org/licenses/by/ $4.0 /)$.

\begin{abstract}
Protein tyrosine kinases and protein phosphatases play a critical role in cellular regulation. The length of a cellular response depends on the interplay between activating protein kinases and deactivating protein phosphatases. Protein tyrosine phosphatase 1B (PTP1B) and growth factor receptor-bound protein 14 (Grb14) are negative regulators of receptor tyrosine kinases. However, in the retina, we have previously shown that PTP1B inactivates insulin receptor signaling, whereas phosphorylated Grb14 inhibits PTP1B activity. In silico docking of phosphorylated Grb14 and PTP1B indicate critical residues in PTP1B that may mediate the interaction. Phosphoinositides (PIPs) are acidic lipids and minor constituents in the cell that play an important role in cellular processes. Their levels are regulated by growth factor signaling. Using phosphoinositide binding protein probes, we observed increased levels of $\mathrm{PI}(3) \mathrm{P}, \mathrm{PI}(4) \mathrm{P}, \mathrm{PI}(3,4) \mathrm{P}_{2}, \mathrm{PI}(4,5) \mathrm{P} 2$, and $\mathrm{PI}(3,4,5) \mathrm{P}_{3}$ in $\mathrm{PTP} 1 \mathrm{~B}$ knockout mouse retina and decreased levels of these PIPs in Grb14 knockout mouse retina. These observations suggest that the interplay between PTP1B and Grb14 can regulate PIP metabolism.
\end{abstract}

Keywords: phosphoinositides; retina; photoreceptor cells; membrane binding; light activation; PTP1B; Grb14

\section{Introduction}

Protein tyrosine phosphatase 1B (PTP1B) and growth factor receptor-bound protein (Grb14) are two negative regulators of insulin receptor (IR) and insulin-like growth factor 1 receptor (IGF-1R) [1,2]. We previously reported that PTP1B and Grb14 are expressed in various layers of the retina, including photoreceptor cells, where IR and IGF-1R are expressed [3]. Furthermore, we noted increased PTP1B activity in the dark-adapted retina, and decreased PTP1B activity was observed in the light-adapted conditions [4]. PTP1B belongs to the protein tyrosine phosphatase family, dephosphorylates insulin and IGF1 receptors, and inactivates IR and IGF1R signaling [1]. Either conditional deletion of PTP1B in rods or global PTP1B deletion resulted in enhanced retinal neuroprotection $[4,5]$, whereas mouse rods lacking insulin receptors are susceptible to light-induced photoreceptor degeneration [6]. In cones, deletion of IR resulted in cone degeneration in the absence of stress [7].

Grb14 is a pseudosubstrate inhibitor of the IR, which interacts with IR's substrate binding site and selectively inhibits the IR kinase activity [2]. Tissue-specific effects have been observed when mice lack Grb14. Increased insulin sensitivity and enhanced glucose tolerance have been observed in the liver and skeletal muscle of Grb14 KO mice [8]. 
However, in the liver, a decreased IR phosphorylation has been observed as a result of increased protein tyrosine phosphatase activity [8]. In the retina, loss of Grb14 resulted in the loss of light-induced tyrosine phosphorylation of the IR [3]. In cardiac muscle, ablation of Grb14 led to decreased phosphoinositide 3-kinase (PI3K)/Akt activation and myocardial infarction [9]. The retina is a post-mitotic tissue, and downregulation of growth factor signaling is detrimental to retinal neurons. Both PTP1B and Grb14 negatively regulate insulin and IGF1R signaling. How do the retinal IR and IGF1R overcome the inhibition by PTP1B and Grb14? We previously reported that Grb14 undergoes tyrosine phosphorylation by a non-receptor tyrosine kinase, Src, and the phosphorylated Grb14 competitively inhibits PTP1B [10]. Upon PTP1B inhibition, the IR and IGF1 receptors activate the downstream PI3K/Akt activation.

Phosphoinositide lipids (also known as phosphatidylinositol phosphates or PIPs) are minor constitutes of phospholipids [11]. Phosphoinositides are generated by the parent molecule phosphatidylinositol, which consists of a myo-inositol head group, a glycerol backbone, and two fatty acids attached to the $\mathrm{C} 1$ and $\mathrm{C} 2$ position of glycerol [12]. Phosphorylation of free-hydroxyl on 3, 4, 5 positions on the inositol ring by phosphoinositide kinases resulted in the generation of seven phosphorylated phosphoinositides (PIPs): PI(3)P, PI(4)P, PI(5)P, PI(3,4) $\mathrm{P}_{2}, \mathrm{PI}(3,5) \mathrm{P}_{2}, \mathrm{PI}(4,5) \mathrm{P}_{2}$, and $\mathrm{PI}(3,4,5) \mathrm{P}_{3}$ (Figure 1). These PIPs play an important role in membrane budding and fusion, ciliogenesis, cytoskeletal assembly, vesicular trafficking, and signal transduction [11]. In the present study, we examined the levels of phosphoinositide lipids in PTP1B and Grb14 KO mice.

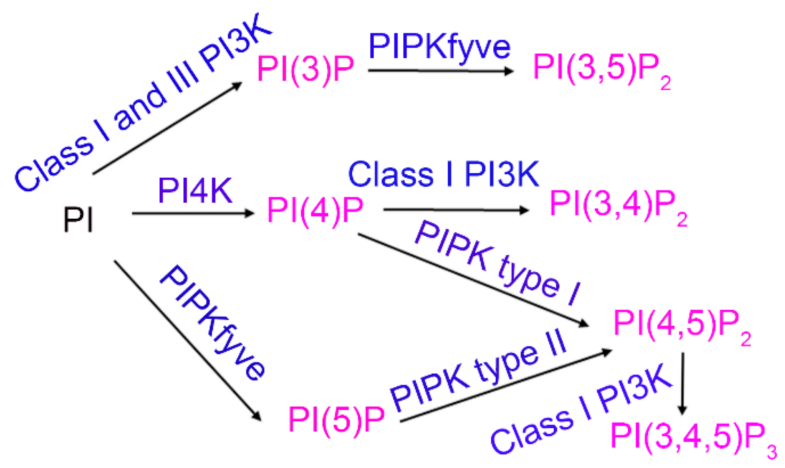

Figure 1. Generation of seven phosphoinositides. Phosphatidylinositol (PI) undergoes phosphorylation at 3, 4, 5-free hydroxyl groups and generates seven distinct PIPs. Class I phosphoinositide 3-kinase (PI3K) phosphorylates PI to PI(3)P, PI(4)P to $\mathrm{PI}(3,4) \mathrm{P}_{2}$, and $\mathrm{PI}(4,5) \mathrm{P}_{2}$ to $\mathrm{PI}(3,4,5) \mathrm{P}_{3}$. Phosphoinositide 4-kinase (PI4K) phosphorylates PI to PI(4)P. Phosphatidylinositol 3-phosphate 5-kinase (PIKfyve) phosphorylates PI to PI(5)P and PI(3)P to PI(3,5) $\mathrm{P}_{2}$. Type I phosphatidylinositol 4-phosphate 5-kinase (PIPKI) phosphorylates PI(4)P to PI $(4,5) \mathrm{P}_{2}$. Type II phosphatidylinositol 5-phosphate 4-kinase (PIPKII) phosphorylates PI(5)P to PI(4,5) $\mathrm{P}_{2}$. Pink, PIPs; Blue, PIP-kinases.

\section{Materials and Methods}

\subsection{Materials}

Polyclonal Grb14 antibody was generated as described [3]. Polyclonal anti-PTP1B antibody was obtained from Upstate Biotechnology (Lake Placid, NY, USA). The actin antibody was obtained from Affinity BioReagents (Golden, CO, USA). All other reagents were of analytical grade and from Millipore Sigma (St Louis, MO, USA).

\subsection{Animals}

We followed the National Institute of Health (NIH) Guide for the Care and Use of Laboratory Animals and ARVO Statement for the Use of Animals in Ophthalmic and Vision Research. The Institutional Animal Care and Use Committee (IACUC) at the University of Oklahoma Health Sciences Center approved all protocols (Protocol \#13-027). PTP1B KO mice were obtained from Dr. Benjamin Neel (Harvard Medical School). We characterized 
these mice in our previous publication [4]. Grb14 KO mice were a kind gift from Roger J. Daly (Garvan Medical Institute, Sydney, Australia). We characterized these mice in our previous publications $[3,10]$. Retinas were harvested after $\mathrm{CO}_{2}$ asphyxiation and were used for immunoblot and phosphoinositide analyses.

\subsection{Methods}

\subsubsection{Extraction and Measurement of Phosphoinositides from the Retina}

Mouse retinas were homogenized in phosphate-buffered saline (PBS) and the retinal phosphoinositides were extracted as described [13]. Lipid phosphorous was measured according to the method described [14]. Phosphoinositide lipids PI(3)P, PI(4)P, PI(3,4) $\mathrm{P}_{2}$, $\mathrm{PI}(4,5) \mathrm{P}_{2}$, and $\mathrm{PI}(3,4,5) \mathrm{P}_{3}$ were measured by ELISA using PIP-binding protein probes [13]. The obtained luminescence was normalized to phospholipid [15], calculated by measuring lipid phosphorous [14] in the extracted phosphoinositide fraction from the respective retina. We used five mice per group (10 retinas) for the determination PIP levels. Student " $t$ " test was used to compared the significne between the wild-type and KO mouse retinas.

\subsubsection{Immunoblot Analysis}

Immunoblot analysis was carried out as described [3]. The blots were probed with anti-PTP1B (1:1000), anti-Grb14 (1:1000), and anti-actin (1:1000) antibodies overnight at $4{ }^{\circ} \mathrm{C}$. Following overnight incubation in primary antibodies, blots were incubated in either HRP-linked anti-rabbit or anti-mouse secondary antibodies and developed by ECL reagent.

\subsubsection{In Silico Modeling of Grb14 and PTP1B Interactions}

FASTA sequences for mouse Grb14 (Q9JLM9) and mouse PTP1B (P35821) were isolated from the UniProt Repository. Sequences were then processed using the SWISSModel [16,17], and using the PTP1B template (1SUG) [18] and Grb14 template (4K81) [19], we generated molecular models of proteins. The programs AutoDock Tools and AutoDock VINA [20] were used to perform docking simulations of the C-terminal tail of Grb14 from amino acids 341-354 [10] as well as phosphorylated Grb14 (pGrb14) peptide from residues 345-352 [10] with the PTP1B binding site. Phosphorylation was performed on Tyr (345, 348,352 ) in silico using the PyMOL plugin PyTMs [21]. The Grb14-PTP1B binding site was estimated to occupy the same region as the PTP1B with the IR binding site (RCSB: 1G1H). The PTP1B binding site was visualized and circumscribed with a grid. Constraints are as follows (center_x $=39.995$, center_y $=15.377$, center_z $=11.841$, size_ $x=20$, size_y $=20$, size_z $=10$, exhaustiveness $=8$ ). Docking was performed with both the unphosphorylated and phosphorylated Grb14 ligand.

Target Preparation: The modeled structure of PTP1B from SWISS-Model was opened in AutoDock Tools. Polar hydrogens were added to PTP1B. The structure was then saved as a pdbqt file using AutoDock Tools.

Ligand Preparation: The Grb14 structure from SWISS-Model was opened in PyMOL and the C-terminal tail of Grb14 was saved as a separate molecule. The PyMOL plugin PyTMs was used to add phosphates to Tyr $(345,348,352)$; the resulting pGrb14 and Grb14 peptides were saved as PDB files. The pGrb14 and Grb14 peptides were individually opened in AutoDock Tools; the torsion count was modified so that the peptide backbone bonds in the Grb14 ligand were non-rotatable, but pGrb14 was rotatable. This was due to desolvation penalties associated with the presence of phosphate groups on alphahelices [22]. Therefore, we opted to allow Vina to postulate the optimal conformation of the pGrb14 with PTP1B by lowering torsional constraints. The resulting ligands were saved as pdbqt files and docked to PTP1B using AutoDock Vina.

\section{Results}

\subsection{Phosphoinositide Levels in PTP1B and Grb14 KO Mouse Retina}

We characterized the PTP1B [4] and Grb14 KO [3,10] mice previously. Immunoblot analysis of eight-week-old wild-type and PTP1B KO mice indicated a loss of $>98 \%$ of PTP1B 
expression in $\mathrm{KO}$ mice compared with wild-type mice (Figure 2A,B). We measured class I PI3K products $\mathrm{PI}(3) \mathrm{P}, \mathrm{PI}(3,4) \mathrm{P}_{2}$, and $\mathrm{PI}(3,4,5) \mathrm{P}_{3}$; class III PI3K product $\mathrm{PI}(3) \mathrm{P}$; PI4-kinase product $\mathrm{PI}(4) \mathrm{P}$; and PIPK1 type I and type II product $\mathrm{PI}(4,5) \mathrm{P}_{2}$. We found significantly increased levels of $\mathrm{PI}(3) \mathrm{P}, \mathrm{PI}(4) \mathrm{P}, \mathrm{PI}(3,4) \mathrm{P}_{2}, \mathrm{PI}(4,5) \mathrm{P}_{2}$, and $\mathrm{PI}(3,4,5) \mathrm{P}_{3}$ in PTP1B knockout mouse retinas compared with control littermates (Figure $2 \mathrm{C}-\mathrm{G}$ ). Immunoblot analysis of eight-week-old wild-type and Grb14 KO mice indicated a loss >81\% of Grb14 in KO mice compared to wild-type mice (Figure 3A,B). We observed the residual Grb14 antibody immunoreactive band on immunoblots [23]. We previously reported that this band is not blocked by the blocking peptide [3]. Mouse retinas lacking Grb14 showed significantly decreased levels of $\mathrm{PI}(3) \mathrm{P}, \mathrm{PI}(4) \mathrm{P}, \mathrm{PI}(3,4) \mathrm{P}_{2}, \mathrm{PI}(4,5) \mathrm{P}_{2}$, and $\mathrm{PI}(3,4,5) \mathrm{P}_{3}$ compared with wildtype littermates (Figure $3 \mathrm{C}-\mathrm{G}$ ).
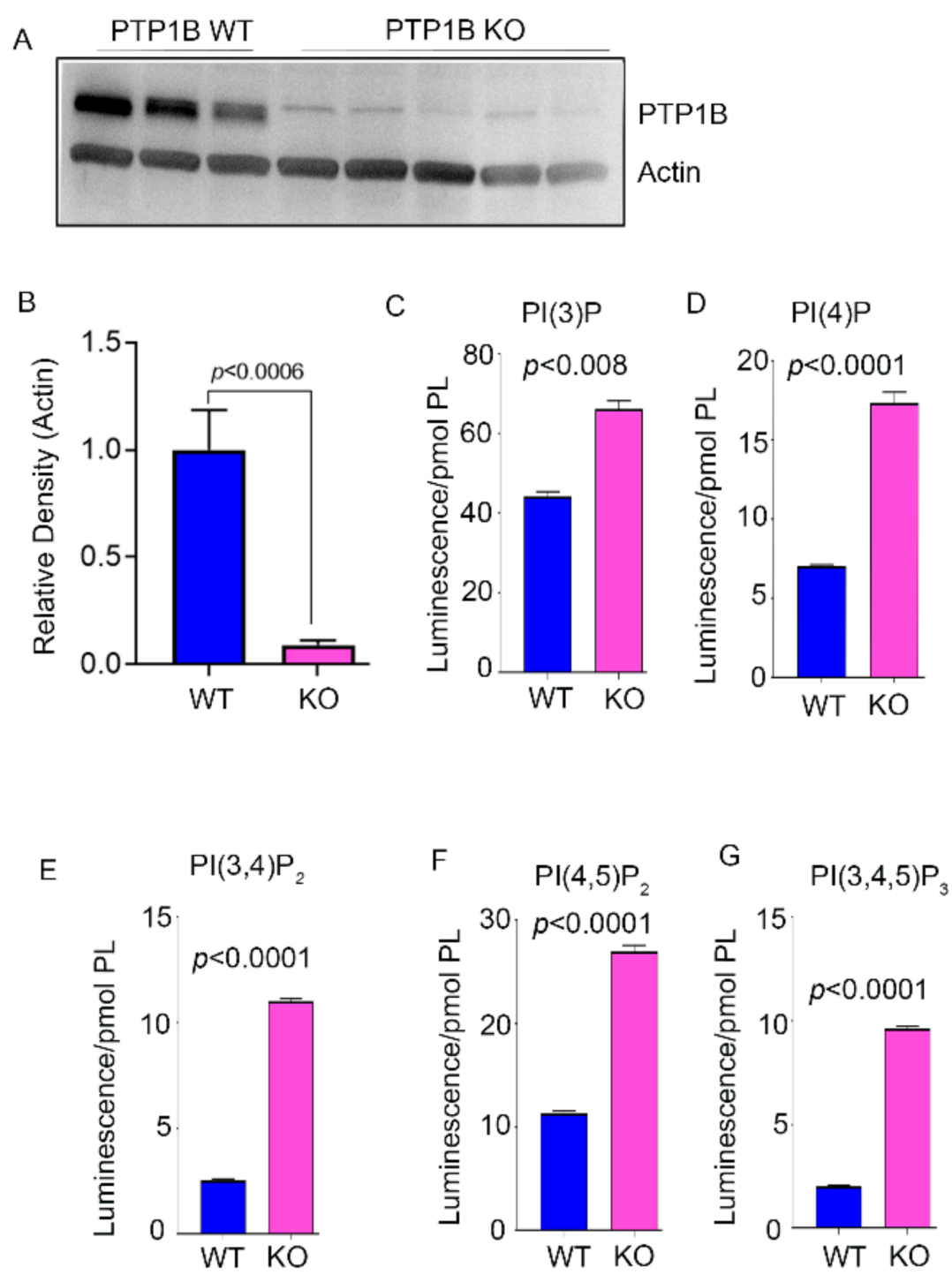

Figure 2. Determination of the levels of PIPs in the PTP1B knockout mouse retina. Wild-type and PTP1B KO mouse retina lysates were immunoblotted with anti PTP1B and anti-actin (A) antibodies. Densitometric analysis of PTP1B was normalized to actin (B). Data are mean \pm SEM, (WT, $n=4 ; \mathrm{KO}$, $n=5$ ). Student $t$-test was used to compare the significance between groups. Phosphoinositides were extracted from PTP1B KO and wild-type control littermates. The PIP lipids were coated on the ELISA plate and we measured $\mathrm{PI}(3) \mathrm{P}, \mathrm{PI}(4) \mathrm{P}, \mathrm{PI}(3,4) \mathrm{P}_{2}, \mathrm{PI}(4,5) \mathrm{P}_{2}$, and $\mathrm{PI}(3,4,5) \mathrm{P}_{3}$ levels using PI-binding proteins as probes $(\mathbf{B}-\mathbf{G})$. Data are mean $\pm \operatorname{SEM}(n=3)$. The significance is indicated on each panel. Full-length blots are presented in Supplementary Information (Figure S1). 


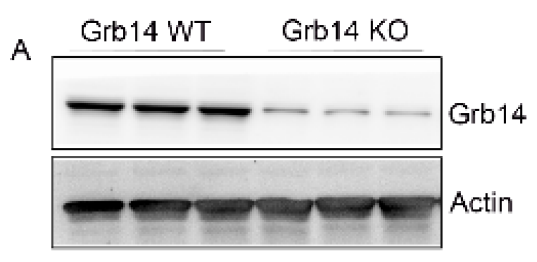

B
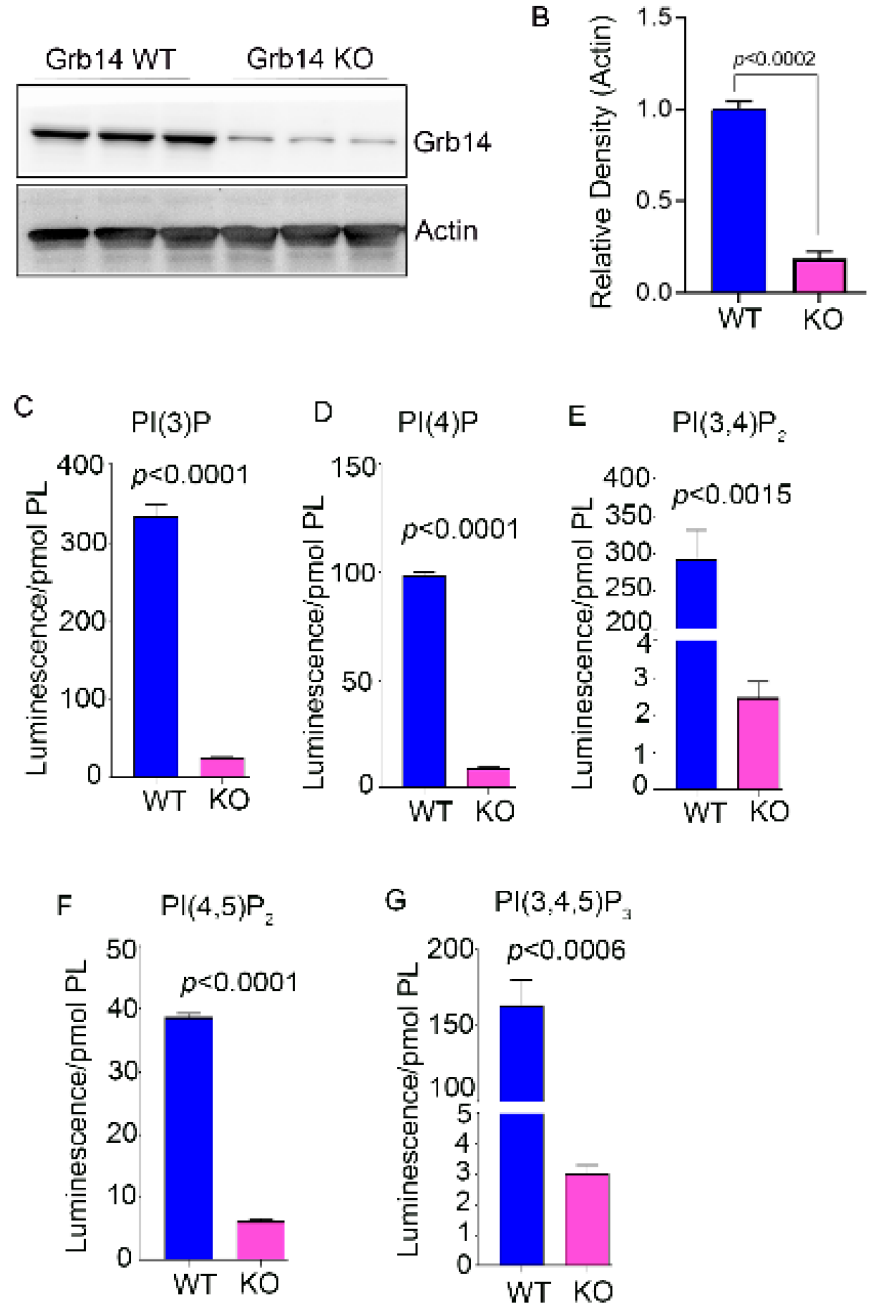

Figure 3. Determination of the levels of PIPs in the Grb14 knockout mouse retina. Wild-type and Grb14 KO mouse retina lysates were immunoblotted with anti Grb14 and anti-actin (A) antibodies. Densitometric analysis of Grb14 was normalized to actin (B). Data are mean \pm SEM, (WT, $n=4 ; \mathrm{KO}$, $n=5)$. Student $t$-test was used to compare the significance between groups. Phosphoinositides were extracted from Grb14 KO and wild-type control littermates. The PIP lipids were coated on the ELISA plate and we measured $\mathrm{PI}(3) \mathrm{P}, \mathrm{PI}(4) \mathrm{P}, \mathrm{PI}(3,4) \mathrm{P}_{2}, \mathrm{PI}(4,5) \mathrm{P}_{2}$, and $\mathrm{PI}(3,4,5) \mathrm{P}_{3}$ levels using PI-binding proteins as probes $(\mathbf{C}-\mathbf{G})$. Data are mean $\pm \operatorname{SEM}(n=3)$. The significance is indicated on each panel. Full-length blots are presented in Supplementary Information (Figure S1).

\subsection{Identification of Putative Residues in PTP1B That Mediate the Interaction with Grb14}

We have identified the minimum peptide region in Grb14 that is involved in the inhibition of PTP1B activity [10]. However, we have not studied the complementary interacting residues in PTP1B. In the present study, we used AutoDock Vina to identify binding interactions between PTP1B and Grb14 unphosphorylated and phosphorylated peptides. Note, due to the UniProt sequence, the residue count of Grb14 differs by two residues (e.g., Tyr347 becomes Tyr345) from that presented in our previously published paper [10]. Figure 4A shows the full-length Grb14 with docking peptide located at the Cterminus of the protein distal from the pleckstrin homology $(\mathrm{PH})$ domain. Figure $4 \mathrm{~B}$ shows the full-length PTP1B, and the predicted binding site of the Grb14 peptide is annotated. To show the full-length Grb14 in complex with PTP1B, the peptide was docked first and then the full-length protein was aligned to the peptide (Figure 4C, Supplementary Video 1). 


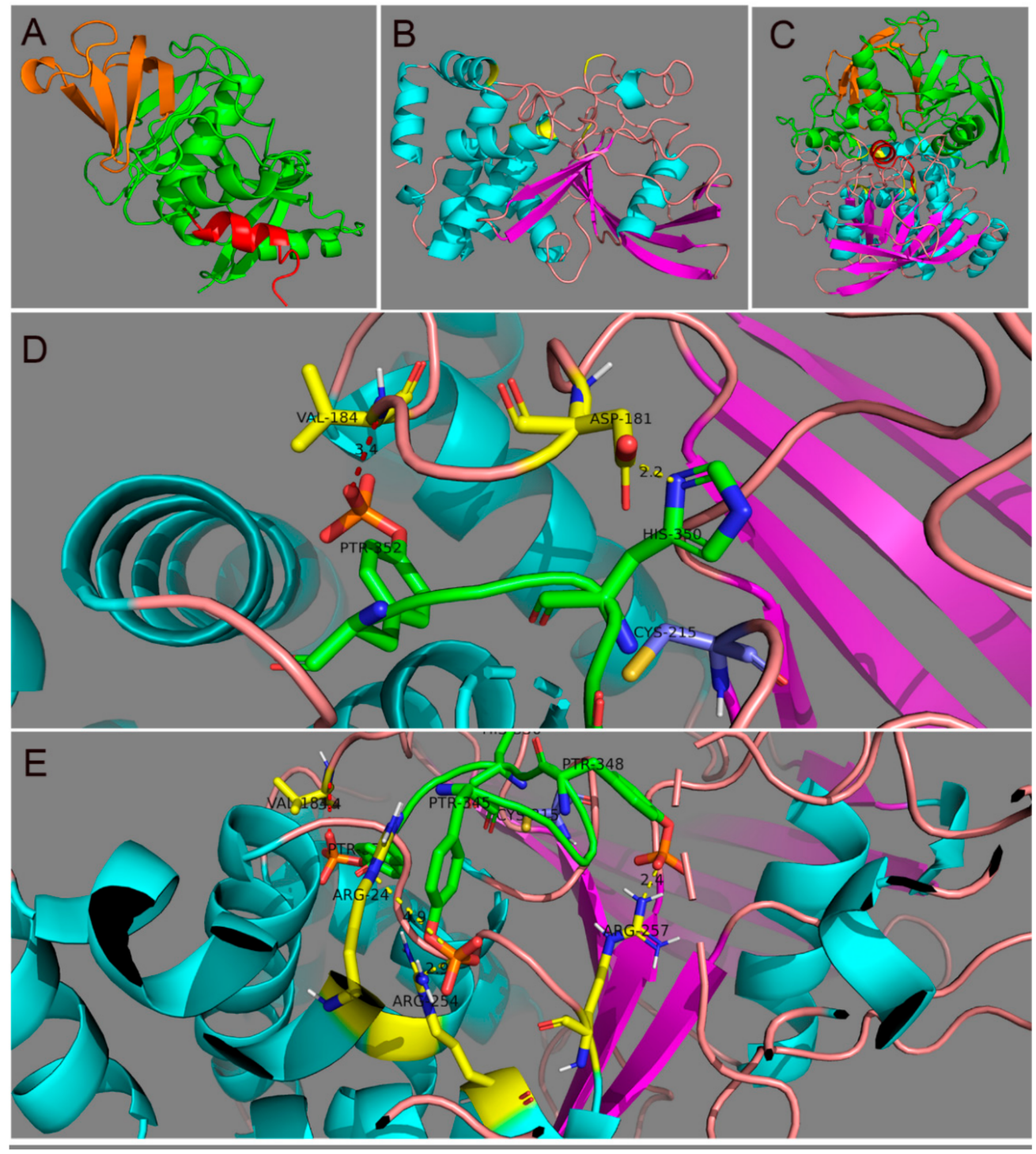

Figure 4. In silico modeling of Grb14 and PTP1B interactions. Cartoon model of Grb14. The binding peptide used for docking simulations is depicted in red. The $\mathrm{PH}$ domain is shown in orange (A). Cartoon model of PTP1B. The alpha helices are depicted in cyan. $\beta$-sheets are shown as purple. The predicted binding site for Grb14 is shown in yellow (B). A complex of Grb14 with PTP1B (C). The predicted binding interaction of the pGrb14 with PTP1B (pTyr352-Val-184; His350-Asp181) (D). The predicted binding interaction of the pGrb14 with PTP1B (pTyr345-Arg24; pTyr345-Arg254; pTyr348-Arg257) (E). Green, pGrb14 peptide; Yellow, putative interacting residues of PTP1B. Video files were provided in the Supplementary Information.

We previously reported that phosphorylated Grb14 (pGrb14) interacts with PTP1B, which results in the inhibition of its activity [10]. The docking analysis revealed possible interactions between pGrb14 and PTP1B that include a hydrogen bond between PTP1B-N-Val184 and pGrb14-pTyr352 (Figure 4D, Supplementary Video 2). We also found a salt bridge between PTP1B-Asp181 and pGrb14-H350 (Figure 4D, Supplementary Video 2). Prior studies have shown that the D181A mutant was able to interact with the substrate, but failed to dephosphorylate [24]. These observations suggest that H350 may interfere with the substrate accession by PTP1B. The pGrb14-pTyr348 interacts with PTP1B-Arg257 through a salt bridge (Figure 4E, Supplementary Video 2). The pGrb14-pTyr345 interacts with PTP1B-NE-Arg24 and PTP1B-Arg254 via salt bridges (Figure 4E, Supplementary Video 2). 


\section{Discussion}

We previously reported that PTP1B deleted mice exhibited enhanced retinal neuroprotection through constitutive activation of retinal insulin receptors [4]. In the retina, loss of Grb14 resulted in decreased IR phosphorylation due to increased PTP1B activity $[3,10]$. Our earlier studies showed that the non-phosphorylated form of Grb14 has a lower affinity for PTP1B than does the phosphorylated form of Grb14 [10] (Figure 5). Further, the in silico modeling predicted the possible interaction between Grb14 and PTP1B. The model predicted that pGrb14-Tyr345 interacts with PTP1B-Arg24 and Arg254 and pGrb14-pTyr348 interacts with PTP1B-Arg257 via salt bridges. Our model prediction also revealed the existence of a salt bridge between pGrb14-H350 and PTP1B-D181. The PTP1B-D181A mutant has previously been used as a substrate trap and identified several PTP1B substrates [24-27]. This mutant accesses the substrate but is unable to release and dephosphorylate the pTyr on the substrates [24]. Our prediction is that the interaction of pGrb14-H350 with PTP1B-D181 suggests a possible interference with the substrate in the inhibition of PTP1B activity.

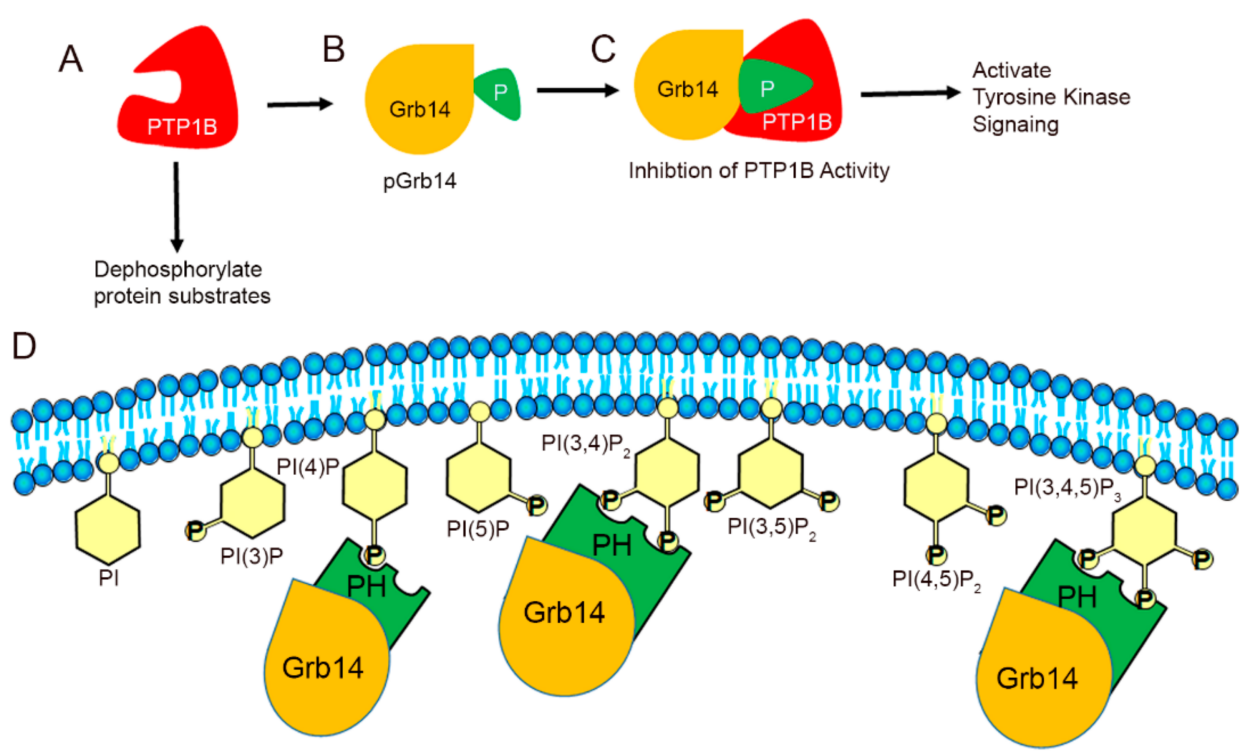

Figure 5. Mechanism of Grb14-mediated inhibition of PTP1B activity in the activation of the receptor tyrosine kinase signaling in the generation of PIPs. PTP1B dephosphorylates the protein substrates and inactivates the PI3K signaling (A). Grb14 undergoes phosphorylation (B) and the phosphorylated Grb14 binds PTP1B and inhibits its phosphatase activity (C), which results in the activation of the receptor tyrosine signaling, leading to the generation of PIPs $(\mathbf{C})$. The interaction between PIPs and Grb14 (D).

An RMSD value of less than $2 \AA$ may indicate the accuracy of the software. In AutoDock Vina, RMSD values are given by comparing multiple docking poses. However, the use of a macromolecule peptide generated only a few docking poses as opposed to a small ligand. Docking the unphosphorylated-Grb14 peptide gave only one docking pose (estimated affinity $281.6 \mathrm{kcal} / \mathrm{mol}$ ), whereas the phosphorylated-Grb14 peptide gave two docking poses (estimated affinity 113.1/113.8 kcal/mol). The RMSD values between the docking pose for the phosphorylated Grb14 peptide was $3.9 \AA$. It has been well documented in the literature that peptides are more flexible than proteins and tend to adopt numerous conformations [28]. Consistent with the molecular modeling prediction, we previously reported that pGrb14 is a competitive inhibitor of PTP1B [10]. Our in silico model gives us a possible mechanistic insight into how pGrb14 acts as a competitive inhibitor of PTP1B. Further studies, however, are necessary to validate these predictions.

In line with our earlier observations, loss of PTP1B resulted in increased PI(3)P, PI(4)P, $\mathrm{PI}(3,4) \mathrm{P}_{2}, \mathrm{PI}(3,5) \mathrm{P}_{2}$, and $\mathrm{PI}(3,4,5) \mathrm{P}_{3}$, whereas loss of Grb14 decreased these PIPs in the 
retina. Together, these observations suggest that the interplay between PTP1B and Grb14 modulates the key enzymes involved in PIP metabolism. Insulin and IGF1 receptor activation are modulated by PTP1B and Grb14, which in turn regulate class I PI3K, which generates $\mathrm{PI}(3,4) \mathrm{P}_{2}$ and $\mathrm{PI}(3,4,5) \mathrm{P}_{3}$. The observed increase in $\mathrm{PI}(3,4) \mathrm{P}_{2}$ and $\mathrm{PI}(3,4,5) \mathrm{P}_{3}$ in PTP1B KO mouse retina and decreased levels of the PIPs in Grb14 KO mouse retinas suggest the negative and positive regulatory roles of PTP1B and Grb14 on insulin and IGF1 receptors or other tyrosine kinase receptors in the retina. Interestingly, we observed increased levels of $\mathrm{PI}(3) \mathrm{P}, \mathrm{PI}(4) \mathrm{P}$, and $\mathrm{PI}(4,5) \mathrm{P}_{2}$ in $\mathrm{PTP} 1 \mathrm{~B}$ KO mouse retina. Decreased levels of these PIPs in the Grb14 KO mouse retina suggest that the key enzymes involved in the synthesis and degradation of PIPs may also be regulated by the interplay between PTP1B and Grb14. Further studies are needed to confirm these observations. The Grb14 has a PH domain, and we previously reported that it can bind to PIPs in vitro [29]. We speculate that the Grb14-PH domain interacts with membrane PIPs, whereas the C-terminus interacts with PTP1B, thereby promoting growth factor signaling (Figure 5).

Akt, a canonical pro-survival molecule downstream of PI3K, is constitutively active in cone photoreceptors [30]. The addition of the growth factor to retinal explants from rd1 mice resulted in significant activation of Akt [30]. We previously reported that the ablation of Akt2 in the retina resulted in stress-induced photoreceptor degeneration [31]. We also reported that loss of $\mathrm{PI} 3 \mathrm{~K}$, which makes $\mathrm{PI}(3,4,5) \mathrm{P}_{3}$ in cones, resulted in age-related cone degeneration [32]. Disruption of Akt signal transduction significantly contributes to the pathogenesis of various neurodegenerative diseases, such as Parkinson's disease, Alzheimer's disease, Huntington's disease, and many others [33].

In the retina, there is an active PIP cycle that responds to light [12,34]. Both class I PI3K and class III P3K signaling pathways are essential for cone photoreceptor function and survival [32,35], whereas class III P3K is essential for rod photoreceptor [36], rod bipolar [37], and retinal pigment epithelium cell functions [38]. In the retina, PIPs play an important role in channel modulation, phototransduction, vesicular transport, ciliogenesis, and cell survival [12,34]. Furthermore, mutations in phosphoinositide phosphatases play an important role in retinal diseases. Mutations in synaptojanin 1 in zebrafish cone photoreceptors show an abnormal buildup of late endosomes and autophagosomes [39]. Defects in oculocerebroretinal syndromes of Lowe (OCRL) phosphatase are associated with glaucoma [40], and mutations in inositol polyphosphatase (INPP5E) are associated with Bardet-Bedi and Joubert syndrome, which leads to retinal degeneration [41,42]. The novel observations made on the interplay between PTP1B and Grb14 on PIPs in the present study suggest that other regulatory proteins may influence the PIP metabolism.

\section{Conclusions}

Phosphoinositide lipids play an important role in cellular processes. In cells, PIPs are formed by the action of phosphoinositide kinases and phosphoinositide phosphatases. Class I phosphoinositide 3-kinase activation via growth factor signaling enhances $\mathrm{PI}(3,4) \mathrm{P}_{2}$ and PI $(3,4,5) \mathrm{P}_{3}$. In the current study, we showed that two regulators of the receptor tyrosine kinase signaling, PTP1B and Grb14, modulate the levels of PIPs in the retina. Our studies also showed modulations in the levels of $\mathrm{PI}(3) \mathrm{P}, \mathrm{PI}(4) \mathrm{P}$, and $\mathrm{PI}(4,5) \mathrm{P}_{2}$ in $\mathrm{PTP} 1 \mathrm{~B}$ and Grb14 KO mouse retina, suggesting that the enzymes involved in the generation of these PIPs may also be influenced by the interplay between PTP1B and Grb14. Furthermore, our in silico docking of phosphorylated Grb14 and PTP1B indicate critical residues in PTP1B that may mediate the interaction.

Supplementary Materials: The following are available online at https:/ / www.mdpi.com/article/10 .3390/biom11040602/s1, Figure S1: Full-length immunoblots, Video S1: docking of full-length Grb14 in complex with PTP1B, Video S2: docking of pGrb14 peptide with PTP1B. 
Author Contributions: R.V.S.R. designed the research. R.V.S.R., A.M., K.T., and A.R. performed the research. R.V.S.R., A.M., and A.R. analyzed the data. R.R. carried out the in silico structure model predictions and R.V.S.R. interpreted the results. R.V.S.R. wrote the paper. All authors have read and agreed to the published version of the manuscript.

Funding: This research was funded by grants from the National Institutes of Health (EY00871, EY030024, and NEI Core grant EY12190), the BrightFocus Foundation, Inc., Oklahoma Center for Adult Stem Cell Research, and an unrestricted grant from Research to Prevent Blindness, Inc. to the OUHSC Department of Ophthalmology supported this study. The APC was funded by EY030024.

Institutional Review Board Statement: We followed the National Institute of Health (NIH) Guide for the Care and Use of Laboratory Animals and ARVO Statement for the Use of Animals in Ophthalmic and Vision Research. The Institutional Animal Care and Use Committee (IACUC) at the University of Oklahoma Health Sciences Center approved all protocols (Protocol \#13-027).

Acknowledgments: We thank Roger J. Day (Garvan Medical Institute, Sydney Australia) for providing us with Grb14 KO mice and Benjamin Neel (Harvard Medical School, Boston) for providing us with PTP1B KO mice. The authors also acknowledge Kathy J. Kyler, Staff Editor, University of Oklahoma Health Sciences Center, for editing this manuscript.

Conflicts of Interest: The authors declare no conflicts of interest.

\section{References}

1. Stuible, M.; Tremblay, M.L. In control at the ER: PTP1B and the down-regulation of RTKs by dephosphorylation and endocytosis. Trends Cell Biol. 2010, 20, 672-679. [CrossRef]

2. Depetris, R.S.; Hu, J.; Gimpelevich, I.; Holt, L.J.; Daly, R.J.; Hubbard, S.R. Structural basis for inhibition of the insulin receptor by the adaptor protein Grb14. Mol. Cell 2005, 20, 325-333. [CrossRef]

3. Rajala, A.; Daly, R.J.; Tanito, M.; Allen, D.T.; Holt, L.J.; Lobanova, E.S.; Arshavsky, V.Y.; Rajala, R.V. Growth factor receptor-bound protein 14 undergoes light-dependent intracellular translocation in rod photoreceptors: Functional role in retinal insulin receptor activation. Biochemistry 2009, 48, 5563-5572. [CrossRef]

4. Rajala, R.V.; Tanito, M.; Neel, B.G.; Rajala, A. Enhanced retinal insulin receptor-activated neuroprotective survival signal in mice lacking the protein-tyrosine phosphatase-1B gene. J. Biol. Chem. 2010, 285, 8894-8904. [CrossRef] [PubMed]

5. Rajala, R.V.; Rajala, A. Neuroprotective role of protein tyrosine phosphatase-1B in rod photoreceptor neurons. Protein Cell 2013, 4 , 890-892. [CrossRef] [PubMed]

6. Rajala, A.; Tanito, M.; Le, Y.Z.; Kahn, C.R.; Rajala, R.V. Loss of neuroprotective survival signal in mice lacking insulin receptor gene in rod photoreceptor cells. J. Biol. Chem. 2008, 283, 19781-19792. [CrossRef] [PubMed]

7. Rajala, A.; Wang, Y.; Rajala, R.V. Activation of oncogenic tyrosine kinase signaling promotes insulin receptor-mediated cone photoreceptor survival. Oncotarget 2016, 7, 46924-46942. [CrossRef] [PubMed]

8. Cooney, G.J.; Lyons, R.J.; Crew, A.J.; Jensen, T.E.; Molero, J.C.; Mitchell, C.J.; Biden, T.J.; Ormandy, C.J.; James, D.E.; Daly, R.J Improved glucose homeostasis and enhanced insulin signalling in Grb14-deficient mice. EMBO J. 2004, 23, 582-593. [CrossRef] [PubMed]

9. Lin, R.C.; Weeks, K.L.; Gao, X.M.; Williams, R.B.; Bernardo, B.C.; Kiriazis, H.; Matthews, V.B.; Woodcock, E.A.; Bouwman, R.D.; Mollica, J.P.; et al. PI3K(p110 alpha) protects against myocardial infarction-induced heart failure: Identification of PI3K-regulated miRNA and mRNA. Arterioscler. Thromb. Vasc. Biol. 2010, 30, 724-732. [CrossRef] [PubMed]

10. Basavarajappa, D.K.; Gupta, V.K.; Dighe, R.; Rajala, A.; Rajala, R.V. Phosphorylated Grb14 Is an Endogenous Inhibitor of Retinal Protein Tyrosine Phosphatase 1B, and Light-Dependent Activation of Src Phosphorylates Grb14. Mol. Cell Biol. 2011, 31, $3975-3987$. [CrossRef] [PubMed]

11. Balla, T. Phosphoinositides: Tiny lipids with giant impact on cell regulation. Physiol. Rev. 2013, 93, 1019-1137. [CrossRef] [PubMed]

12. Rajala, R.V.S. Signaling roles of phosphoinositides in the retina. J. Lipid Res. 2021, 100041. [CrossRef] [PubMed]

13. Rajala, A.; McCauley, A.; Brush, R.S.; Nguyen, K.; Rajala, R.V.S. Phosphoinositide Lipids in Ocular Tissues. Biology 2020, 9 , 125. [CrossRef]

14. Rouser, G.; Siakotos, A.N.; Fleischer, S. Quantitative analysis of phospholipids by thin-layer chromatography and phosphorus analysis of spots. Lipids 1966, 1, 85-86. [CrossRef] [PubMed]

15. Gortner, W.A. An evaluation of micromethods for phospholipids. J. Biol. Chem. 1945, 159, 97-100. [CrossRef]

16. Bienert, S.; Waterhouse, A.; de Beer, T.A.; Tauriello, G.; Studer, G.; Bordoli, L.; Schwede, T. The SWISS-MODEL Repository-new features and functionality. Nucleic Acids Res. 2017, 45, D313-D319. [CrossRef]

17. Waterhouse, A.; Bertoni, M.; Bienert, S.; Studer, G.; Tauriello, G.; Gumienny, R.; Heer, F.T.; de Beer, T.A.P.; Rempfer, C.; Bordoli, L.; et al. SWISS-MODEL: Homology modelling of protein structures and complexes. Nucleic Acids Res. 2018, 46, W296-W303. [CrossRef] 
18. Pedersen, A.K.; Peters, G.G.; Møller, K.B.; Iversen, L.F.; Kastrup, J.S. Water-molecule network and active-site flexibility of apo protein tyrosine phosphatase 1B. Acta Crystallogr. Sect. D Biol. Crystallogr. 2004, 60, 1527-1534. [CrossRef]

19. Qamra, R.; Hubbard, S.R. Structural basis for the interaction of the adaptor protein grb14 with activated ras. PLoS ONE 2013, 8 , e72473. [CrossRef]

20. Trott, O.; Olson, A.J. AutoDock Vina: Improving the speed and accuracy of docking with a new scoring function, efficient optimization, and multithreading. J. Comput. Chem. 2010, 31, 455-461. [CrossRef]

21. Warnecke, A.; Sandalova, T.; Achour, A.; Harris, R.A. PyTMs: A useful PyMOL plugin for modeling common post-translational modifications. BMC Bioinform. 2014, 15, 370. [CrossRef]

22. Andrew, C.D.; Warwicker, J.; Jones, G.R.; Doig, A.J. Effect of phosphorylation on alpha-helix stability as a function of position Biochemistry 2002, 41, 1897-1905. [CrossRef]

23. Gupta, V.K.; Rajala, A.; Daly, R.J.; Rajala, R.V. Growth factor receptor-bound protein 14: A new modulator of photoreceptor-specific cyclic-nucleotide-gated channel. EMBO Rep. 2010, 11, 861-867. [CrossRef]

24. Flint, A.J.; Tiganis, T.; Barford, D.; Tonks, N.K. Development of "substrate-trapping" mutants to identify physiological substrates of protein tyrosine phosphatases. Proc. Natl. Acad. Sci. USA 1997, 94, 1680-1685. [CrossRef]

25. Myers, M.P.; Andersen, J.N.; Cheng, A.; Tremblay, M.L.; Horvath, C.M.; Parisien, J.P.; Salmeen, A.; Barford, D.; Tonks, N.K. TYK2 and JAK2 are substrates of protein-tyrosine phosphatase 1B. J. Biol. Chem. 2001, 276, 47771-47774. [CrossRef] [PubMed]

26. Rajala, A.; Dilly, A.K.; Rajala, R.V. Protein tyrosine phosphatase-1B regulates the tyrosine phosphorylation of the adapter Grb2-associated binder 1 (Gab1) in the retina. Cell Commun. Signal. 2013, 11, 20. [CrossRef] [PubMed]

27. Rajala, R.V.; Wiskur, B.; Tanito, M.; Callegan, M.; Rajala, A. Diabetes reduces autophosphorylation of retinal insulin receptor and increases protein-tyrosine phosphatase-1B activity. Investig. Ophthalmol. Vis. Sci. 2009, 50, 1033-1040. [CrossRef] [PubMed]

28. Agrawal, P.; Singh, H.; Srivastava, H.K.; Singh, S.; Kishore, G.; Raghava, G.P.S. Benchmarking of different molecular docking methods for protein-peptide docking. BMC Bioinform. 2019, 19, 426. [CrossRef] [PubMed]

29. Rajala, R.V.; Chan, M.D.; Rajala, A. Lipid-protein interactions of growth factor receptor-bound protein 14 in insulin receptor signaling. Biochemistry 2005, 44, 15461-15471. [CrossRef] [PubMed]

30. Johnson, L.E.; van Veen, T.; Ekstrom, P.A. Differential Akt activation in the photoreceptors of normal and rd1 mice. Cell Tissue Res. 2005, 320, 213-222. [CrossRef]

31. Li, G.; Anderson, R.E.; Tomita, H.; Adler, R.; Liu, X.; Zack, D.J.; Rajala, R.V. Nonredundant role of Akt2 for neuroprotection of rod photoreceptor cells from light-induced cell death. J. Neurosci. 2007, 27, 203-211. [CrossRef]

32. Ivanovic, I.; Anderson, R.E.; Le, Y.Z.; Fliesler, S.J.; Sherry, D.M.; Rajala, R.V. Deletion of the p85alpha regulatory subunit of phosphoinositide 3-kinase in cone photoreceptor cells results in cone photoreceptor degeneration. Invest. Ophthalmol. Vis. Sci. 2011, 52, 3775-3783. [CrossRef]

33. Rai, S.N.; Dilnashin, H.; Birla, H.; Singh, S.S.; Zahra, W.; Rathore, A.S.; Singh, B.K.; Singh, S.P. The Role of PI3K/Akt and ERK in Neurodegenerative Disorders. Neurotox. Res. 2019, 35, 775-795. [CrossRef]

34. Wensel, T.G. Phosphoinositides in Retinal Function and Disease. Cells 2020, 9, 866. [CrossRef] [PubMed]

35. Rajala, A.; He, F.; Anderson, R.E.; Wensel, T.G.; Rajala, R.V.S. Loss of Class III Phosphoinositide 3-Kinase Vps34 Results in Cone Degeneration. Biology 2020, 9, 384. [CrossRef]

36. He, F.; Agosto, M.A.; Anastassov, I.A.; Tse, D.Y.; Wu, S.M.; Wensel, T.G. Phosphatidylinositol-3-phosphate is light-regulated and essential for survival in retinal rods. Sci. Rep. 2016, 6, 26978. [CrossRef] [PubMed]

37. He, F.; Nichols, R.M.; Kailasam, L.; Wensel, T.G.; Agosto, M.A. Critical Role for Phosphatidylinositol-3 Kinase Vps34/PIK3C3 in ON-Bipolar Cells. Investig. Ophthalmol. Vis. Sci. 2019, 60, 2861-2874. [CrossRef] [PubMed]

38. He, F.; Agosto, M.A.; Nichols, R.M.; Wensel, T.G. Multiple phosphatidylinositol(3)phosphate roles in retinal pigment epithelium membrane recycling. bioRxiv 2020. [CrossRef]

39. Van Epps, H.A.; Hayashi, M.; Lucast, L.; Stearns, G.W.; Hurley, J.B.; De Camilli, P.; Brockerhoff, S.E. The zebrafish nrc mutant reveals a role for the polyphosphoinositide phosphatase synaptojanin 1 in cone photoreceptor ribbon anchoring. J. Neurosci. 2004, 24, 8641-8650. [CrossRef]

40. Prosseda, P.P.; Luo, N.; Wang, B.; Alvarado, J.A.; Hu, Y.; Sun, Y. Loss of OCRL increases ciliary PI $(4,5) P(2)$ in Lowe oculocerebrorenal syndrome. J. Cell Sci. 2017, 130, 3447-3454. [CrossRef]

41. Luo, N.; Conwell, M.D.; Chen, X.; Kettenhofen, C.I.; Westlake, C.J.; Cantor, L.B.; Wells, C.D.; Weinreb, R.N.; Corson, T.W.; Spandau, D.F.; et al. Primary cilia signaling mediates intraocular pressure sensation. Proc. Nat. Acad. Sci. USA 2014, 111, 12871-12876. [CrossRef]

42. Travaglini, L.; Brancati, F.; Silhavy, J.; Iannicelli, M.; Nickerson, E.; Elkhartoufi, N.; Scott, E.; Spencer, E.; Gabriel, S.; Thomas, S.; et al. Phenotypic spectrum and prevalence of INPP5E mutations in Joubert syndrome and related disorders. Eur. J. Hum. Genet. 2013, 21, 1074-1078. [CrossRef] 